University of Nebraska - Lincoln

DigitalCommons@University of Nebraska - Lincoln

4-2007

\title{
Complexity Leadership Theory: Shifting leadership from the industrial age to the knowledge era
}

\author{
Mary Uhl-Bien \\ University of Nebraska-Lincoln, mbien2@unl.edu \\ Russ Marion \\ Clemson University, Clemson, SC, marion2@clemson.edu \\ Bill McKelvey \\ The UCLA Anderson School of Management, mckelvey@anderson.ucla.edu
}

Follow this and additional works at: https://digitalcommons.unl.edu/leadershipfacpub

Part of the Management Sciences and Quantitative Methods Commons

Uhl-Bien, Mary; Marion, Russ; and McKelvey, Bill, "Complexity Leadership Theory: Shifting leadership from the industrial age to the knowledge era" (2007). Leadership Institute Faculty Publications. 18.

https://digitalcommons.unl.edu/leadershipfacpub/18

This Article is brought to you for free and open access by the Leadership Institute at DigitalCommons@University of Nebraska - Lincoln. It has been accepted for inclusion in Leadership Institute Faculty Publications by an authorized administrator of DigitalCommons@University of Nebraska - Lincoln. 
Published in The Leadership Quarterly 18:4 (August 2007), pp. 298-318; Special Issue on

Leadership and Complexity; doi 10.1016/j.leaqua.2007.04.002

Copyright (C) 2007 Elsevier Inc. Used by permission.

http://www.sciencedirect.com/science/journal/10489843

An earlier version of this paper was presented at the National Academy of Management Meeting

in New Orleans, Louisiana, August 2004.

Published online June 11, 2007.

\title{
Complexity Leadership Theory: Shifting leadership from the industrial age to the knowledge era
}

\author{
Mary Uhl-Bien \\ Corresponding author: Department of Management, University of Nebraska-Lincoln, \\ P.O. Box 880491, Lincoln, NE 68588-0491, USA; tel 402 472-2314, email muhlbien@unlnotes.unl.edu \\ Russ Marion \\ Educational Leadership, School of Education, Clemson University, \\ Clemson, SC 29631-0710, USA; tel 864 656-5105, email Marion2@clemson.edu \\ Bill McKelvey \\ The UCLA Anderson School of Management, 110 Westwood Plaza, \\ Los Angeles, CA 90095-1481, USA; tel 310 825-7796, email mckelvey@anderson.ucla.edu
}

\begin{abstract}
Leadership models of the last century have been products of top-down, bureaucratic paradigms. These models are eminently effective for an economy premised on physical production but are not well-suited for a more knowledgeoriented economy. Complexity science suggests a different paradigm for leadership-one that frames leadership as a complex interactive dynamic from which adaptive outcomes (e.g., learning, innovation, and adaptability) emerge. This article draws from complexity science to develop an overarching framework for the study of Complexity Leadership Theory, a leadership paradigm that focuses on enabling the learning, creative, and adaptive capacity of complex adaptive systems (CAS) within a context of knowledge-producing organizations. This conceptual framework includes three entangled leadership roles (i.e., adaptive leadership, administrative leadership, and enabling leadership) that reflect a dynamic relationship between the bureaucratic, administrative functions of the organization and the emergent, informal dynamics of complex adaptive systems (CAS).
\end{abstract}

Keywords: leadership, complexity theory, complex adaptive systems (CAS), Knowledge Era, creativity, adaptive organizations, bureaucracy

As we advance deeper in the knowledge economy, the basic assumptions underlining much of what is taught and practiced in the name of management are hopelessly out of date...Most of our assumptions about business, technology and organization are at least 50 years old. They have outlived their time. (Drucker, 1998, p. 162)

We're in a knowledge economy, but our managerial and governance systems are stuck in the Industrial Era. It's time for a whole new model. (Manville \& Ober, 2003, Jan., p. 48) 
According to Hitt (1998), "we are on the precipice of an epoch," in the midst of a new economic age, in which 21st century organizations are facing a complex competitive landscape driven largely by globalization and the technological revolution. This new age is about an economy where knowledge is a core commodity and the rapid production of knowledge and innovation is critical to organizational survival (Bettis \& Hitt, 1995; Boisot, 1998). Consistent with these changes, much discussion is taking place in the management literature regarding challenges facing organizations in a transitioning world (Barkema et al., 2002; Bettis \& Hitt, 1995; Child \& McGrath, 2001).

Yet, despite the fact that leadership is a core factor in whether organizations meet these challenges, we find little explicit discussion of leadership models for the Knowledge Era. As noted by Davenport (2001), while it has become clear that the old model of leadership was formed to deal with a very different set of circumstances and is therefore of questionable relevance to the contemporary work environment, no clear alternative has come along to take its place. Osborn, Hunt, \& Jauch (2002) argue that "a radical change in perspective" about leadership is necessary to go beyond traditionally accepted views, because "...the context in which leaders operate is both radically different and diverse. The world of traditional bureaucracy exists but it is only one of many contexts" (p. 798).

We begin to address this shortcoming by developing a framework for leadership in the fast-paced, volatile context of the Knowledge Era (Marion \& Uhl-Bien, 2001; Schneider \& Somers, 2006). Our model extends beyond bureaucracy premises by drawing from complexity science, the "study of the behaviour of large collections of ... simple, interacting units, endowed with the potential to evolve with time" (Coveney, 2003, p. 1058). Using the concept of complex adaptive systems (CAS), we propose that leadership should be seen not only as position and authority but also as an emergent, interactive dynamic-a complex interplay from which a collective impetus for action and change emerges when heterogeneous agents interact in networks in ways that produce new patterns of behavior or new modes of operating (cf. Heifetz, 1994; Plowman et al., 2007; Plowman \& Duchon, in press).

Complex adaptive systems (CAS) are a basic unit of analysis in complexity science. CAS are neurallike networks of interacting, interdependent agents who are bonded in a cooperative dynamic by common goal, outlook, need, etc. They are changeable structures with multiple, overlapping hierarchies, and like the individuals that comprise them, CAS are linked with one another in a dynamic, interactive network. Hedlund (1994) describes a generally similar structure relative to managing knowledge flows in organizations that he called "temporary constellations of people and units" (p. 82). CAS emerge naturally in social systems (cf. Homans, 1950; Roy, 1954). They are capable of solving problems creatively and are able to learn and adapt quickly (Carley \& Hill, 2001; Carley \& Lee, 1998; Goodwin, 1994; Levy, 1992).

The leadership framework we propose, which we call Complexity Leadership Theory, seeks to take advantage of the dynamic capabilities of CAS. Complexity Leadership Theory (CLT) focuses on identifying and exploring the strategies and behaviors that foster organizational and subunit creativity, learning, and adaptability when appropriate CAS dynamics are enabled within contexts of hierarchical coordination (i.e., bureaucracy). In CLT, we recognize three broad types of leadership: (1) leadership grounded in traditional, bureaucratic notions of hierarchy, alignment and control (i.e., administrative leadership), (2) leadership that structures and enables conditions such that CAS are able to optimally address creative problem solving, adaptability, and learning (referring to what we will call, enabling leadership); and (2) leadership as a generative dynamic that underlies emergent change activities (what we will call, adaptive leadership).

The Complexity Leadership perspective is premised on several critical notions. First, the informal dynamic we describe is embedded in context (Hunt, 1999; Osborn et al., 2002). Context in complex adaptive systems is not an antecedent, mediator, or moderator variable; rather, it is the ambiance that spawns a given system's dynamic persona - in the case of complex system personae, it refers to the nature of interactions and interdependencies among agents (people, ideas, etc.), hierarchical divisions, organizations, and environments. CAS and leadership are socially constructed in and from this context - a context in which patterns over time must be considered and where history matters (Cilliers, 1998; Dooley, 1996; Hosking, 1988; Osborn et al., 2002).

Second, a complexity leadership perspective requires that we distinguish between leadership and leaders. Complexity Leadership Theory will add a view of leadership as an emergent, interactive dynamic that is productive of adaptive outcomes (which we call adaptive leadership, cf. Heifetz, 1994). It will consider leaders as individuals who act in ways that influence this dynamic and the outcomes. Leadership theory has largely focused on leaders - the actions of individuals. It has not examined the dynamic, complex systems and processes that comprise leadership. Because of this, earlier models have been criticized for being incomplete 
and impractical (Gronn, 1999; Osborn et al., 2002]; see also Hunt, 1999). Rost (1991) refers to this as the problem of focusing on the "periphery" and "content" of leadership with disregard for the essential nature of what leadership is - a process (cf. Hunt, 1999; Mackenzie, 2006).

Third, complexity leadership perspectives help us to distinguish leadership from managerial positions or "offices" (a bureaucratic notion, see Heckscher, 1994). The vast majority of leadership research has studied leadership in formal, most often managerial, roles (Bedeian \& Hunt, 2006; Rost, 1991) and has not adequately addressed leadership that occurs throughout the organization (Schneider, 2002). To address this, we will use the term administrative leadership to refer to formal acts that serve to coordinate and structure organizational activities (i.e., the bureaucratic function), and introduce the concept of adaptive leadership to refer to the leadership that occurs in emergent, informal adaptive dynamics throughout the organization (cf. Heifetz, 1994; Heifetz \& Linsky, 2002).

Finally, complexity leadership occurs in the face of adaptive challenges (typical of the Knowledge Era) rather than technical problems (more characteristic of the Industrial Age). As defined by (Heifetz, 1994) and (Heifetz \& Laurie, 2001)), adaptive challenges are problems that require new learning, innovation, and new patterns of behavior. They are different from technical problems, which can be solved with knowledge and procedures already in hand (Parks, 2005). Adaptive challenges are not amenable to authoritative fiat or standard operating procedures, but rather require exploration, new discoveries, and adjustments. Day (2000) refers to this as the difference between management and leadership development. Management development involves the application of proven solutions to known problems, whereas leadership development refers to situations in which groups need to learn their way out of problems that could not have been predicted (e.g., disintegration of traditional organizational structures).

In the sections below we lay out the framework and dynamics we call Complexity Leadership Theory. This framework describes how to enable the learning, creative, and adaptive capacity of complex adaptive systems (CAS) within a context of knowledge-producing organizations. Complexity Leadership Theory seeks to foster CAS dynamics while at the same time enabling control structures for coordinating formal organizations and producing outcomes appropriate to the vision and mission of the organization. We begin by describing the leadership requirements of the Knowledge Era and the limitations of current leadership theory for meeting these requirements. We then describe why CAS dynamics are well suited for the needs of the Knowledge Era, and how leadership can work to enable these dynamics. We conclude with a presentation of the Complexity Leadership Theory framework and a description of the three key leadership functions and roles that comprise this framework: adaptive leadership, enabling leadership, and administrative leadership.

\section{Leadership in the Knowledge Era}

The Knowledge Era is characterized by a new competitive landscape driven by globalization, technology, deregulation, and democratization (Halal \& Taylor, 1999). Many firms deal with this new landscape by allying horizontally and vertically in "constellations" (Bamford, Gomes-Casseres, \& Robinson, 2002). In the process, they actively interconnect the world, creating what some have called a "connectionist era" (Halal, 1998; Miles, 1998]; see Hogue \& Lord, 2007 for an extensive discussion). Through multinational alliances, firms in developing countries now find themselves engaging increasingly in manufacturing activities as producers or subcontractors, while firms in developed economies focus more on information and services (Drucker, 1999). The latter face the need to exhibit speed, flexibility, and adaptability, with the organization's absolute rate of learning and innovation and the pace of its development becoming critical to competitive advantage (Eisenhardt, 1989; Jennings \& Haughton, 2000; Prusak, 1996). In other words, firms in developed economies sustain superior performance in the Knowledge Era by promoting faster learning (Child \& McGrath, 2001).

This new age creates new kinds of challenges for organizations and their leaders (Barkema et al., 2002; Schneider, 2002). In this post-industrial era, the success of a corporation lies more in its social assets-its corporate IQ and learning capacity-than in its physical assets (McKelvey, 2001; Quinn et al., 2002; Zohar, 1997). In the industrial economy, the challenge inside the firm was to coordinate the physical assets produced by employees. This was mainly a problem of optimizing the production and physical flow of products (Boisot, 1998; Schneider, 2002). In the new economy, the challenge is to create an environment in which knowledge accumulates and is shared at a low cost. The goal is to cultivate, protect, and use difficult to imitate knowledge assets as compared to pure commodity-instigated production (Nonaka \& Nishiguchi, 2001). It is a problem of enabling intellectual assets through distributed intelligence and cellular networks (Miles, Snow, Matthews, \& Miles, 1999) rather than relying on the limited intelligence of a few brains at the top (Heckscher, 1994; 
McKelvey, in press). Moreover, the focus is on speed and adaptability (Schilling \& Steensma, 2001). Rather than leading for efficiency and control, appropriate to manufacturing (Jones, 2000), organizations find themselves leading for adaptability, knowledge and learning (Achtenhagen et al., 2003; Volberda, 1996).

To achieve fitness in such a context, complexity science suggests that organizations must increase their complexity to the level of the environment rather than trying to simplify and rationalize their structures. Ashby (1960) refers to this as the law of requisite variety; McKelvey \& Boisot (2003) customized this law for complexity theory and call it the Law of Requisite Complexity. This law states simply that it takes complexity to defeat complexity - a system must possess complexity equal to that of its environment in order to function effectively. Requisite complexity enhances a system's capacity to search for solutions to challenges and to innovate because it releases the capacity of a neural network of agents in pursuit of such optimization. That is, it optimizes a system's capacity for learning, creativity, and adaptability.

As Cilliers (2001) observed, traditional approaches to organization have done the opposite: they have sought to simplify or to rationalize the pursuit of adaptation. He argues that simplifying and rationalizing strategies lead to structures that define fixed boundaries, compartmentalized organizational responses, and simplified coordination and communication (e.g., Simon, 1962). However, such approaches are limited because they do not represent reality-boundaries are not fixed perimeters, but rather, are sets of functions that dynamically interpenetrate one another (Cilliers, 2001). To meet the needs of requisite complexity, Knowledge Era leadership requires a change in thinking away from individual, controlling views, and toward views of organizations as complex adaptive systems that enable continuous creation and capture of knowledge. In short, knowledge development, adaptability, and innovation are optimally enabled by organizations that are complexly adaptive (possessing requisite complexity).

\subsection{Limitations of current leadership theory}

Despite the needs of the Knowledge Era, much of leadership theory remains largely grounded in a bureaucratic framework more appropriate for the Industrial Age (Gronn, 1999). One such element of the bureaucratic concept is the traditional assumption that control must be rationalized. Much of leadership theory is developed around the idea that goals are rationally conceived and that managerial practices should be structured to achieve those goals. As Chester Barnard (1938) framed it, the role of leadership is to align individual preferences with rational organizational goals. Philip Selznick (1948) observed that irrational social forces tend to subvert the formal goals of an institution.

Consistent with this, the dominant paradigm in leadership theory focuses on how leaders can influence others toward desired objectives within frameworks of formal hierarchical organizational structures (Zaccaro \& Klimoski, 2001). This paradigmatic model centers on issues such as motivating workers toward task objectives (House \& Mitchell, 1974), leading them to produce efficiently and effectively (Zaccaro \& Klimoski, 2001) and inspiring them to align with and commit to organizational goals (Bass, 1985). Macro-level theories, such as those that address "upper echelon leadership," are further premised in bureaucratic notions (Heckscher, 1994) that likewise mute uncontrolled behaviors; other models advocate a charismatic, visionary approach that is said to cascade down from the CEO to lower levels (Conger, 1999; Yukl, 2005). Leadership research has explored the implementation of these top-down organizational forms by drilling deeper and deeper into human relations models (aimed at alignment and control; Gronn, 1999; Huxham \& Vangen, 2000).

Without realizing it, the inability to move beyond formal leaders and control inherent in traditional bureaucratic mindsets (Heckscher, 1994) limits the applicability of mainstream leadership theories for the Knowledge Era (Stacey et al., 2000; Streatfield, 2001). There seems to be a contradiction between the needs of the Knowledge Era and the reality of centralized power (Child \& McGrath, 2001) that leadership theory has not yet addressed. "The dominant paradigms in organizational theory are based on stability seeking and uncertainty avoidance through organizational structure and processes. ... We believe that those paradigms are inadequate for global, hyper-competitive environments, although their replacements are not clear yet" (Ilinitch, D'Aveni, \& Lewin, 1996, p. 217). As noted by Child \& McGrath (2001), "Scholars, managers, and others face a widespread challenge to bureaucracy's central benefit, namely, its utility as a vehicle for strong economic performance in the new era" (p. 1136). Leadership scholars face the same challenge:

The ... challenge is to identify alternatives [to bureaucracy] and develop theories that account for them. It is not trivial. How can we improve upon, even replace, such a painstakingly welldeveloped concept of how human beings collectively best accomplish their objectives? (Child \& McGrath, 2001, p. 1136) 
We address this challenge by developing a model of leadership grounded not in bureaucracy, but in complexity. This model focuses on leadership in contexts of dynamically changing networks of informally interacting agents. As will be elaborated below, the premise of complexity leadership is simple: Under conditions of knowledge production, managers should enable, rather than suppress or align, informal network dynamics. Early researchers, such as Lewin (1952) and Homans (1950), glimpsed the potential of such informal dynamics (however vaguely, by complexity theory standards); but the thrust of many follow-up studies of their findings assumed that such informal dynamics were problematic for achieving organizational goals (Roy, 1954; Selznick, 1957). Several recent initiatives have explored the potential of decentralized authority or leadership, including Pearce \& Conger's (2003) work with shared leadership, Gronn's (2002) work on distributed leadership, and Fletcher (2004) and Volberda (1996) on flexible forms. None, however, have developed a model that addresses the nature of leadership for enabling network dynamics, one whose epistemology is consistent with connective, distributed, dynamic, and contextual views of leadership.

We propose such a model in this article, one that we call, Complexity Leadership Theory. This new perspective is grounded in a core proposition: Much of leadership thinking has failed to recognize that leadership is not merely the influential act of an individual or individuals but rather is embedded in a complex interplay of numerous interacting forces.

There are several orienting assumptions that underlie the complexity leadership model; these assumptions will be developed further in this article:

- Complexity Leadership Theory (CLT) is necessarily enmeshed within a bureaucratic superstructure of planning, organizing, and missions. CLT seeks to understand how enabling leaders can interact with the administrative superstructure to both coordinate complex dynamics (i.e., adaptive leadership) and enhance the overall flexibility of the organization (Marion \& Uhl-Bien, 2007).

- Complexity Leadership Theory presumes hierarchical structuring and differing enabling and adaptive functions across levels of the hierarchy.

- The unit of analysis for Complexity Leadership Theory is the CAS. The boundaries of CAS are variously defined depending on the intent of the researcher, but however identified, they are, without exception, open systems.

- Leadership, however it is defined, only exists in, and is a function of, interaction.

Before we elaborate these ideas in our framework below, however, we first must understand why complex adaptive systems are well suited for the Knowledge Era and the dynamics that drive these systems. Therefore, we turn next to an overview of CAS dynamics that will serve as a basis for discussion in subsequent sections.

\subsection{The argument for Complexity Leadership Theory: CAS dynamics}

Earlier we defined complex adaptive systems (or CAS) as open, evolutionary aggregates whose components (or agents) are dynamically interrelated and who are cooperatively bonded by common purpose or outlook. We also introduced Complexity Leadership Theory as a model for leadership in and of complex adaptive systems (CAS) in knowledge-producing organizations. We now ask, "What is so unique about complex adaptive systems theory that it fosters a fresh look at leadership?" and "Why would we want to enable CAS dynamics anyway?"

To answer these questions we need to better understand the structure of CAS and how they are different from systems perspectives offered previously in the organizational literature. As described by Cilliers (1998), complex adaptive systems are different from systems that are merely complicated. If a system can be described in terms of its individual constituents (even if there are a huge number of constituents), it is merely complicated; if the interactions among the constituents of the system, and the interaction between the system and its environment, are of such a nature that the system as a whole cannot be fully understood simply by analyzing its components, it is complex (e.g., a jumbo jet is complicated, but mayonnaise is complex, Cilliers, 1998).

Dooley (1996) describes a CAS as an aggregate of interacting agents that "behaves/evolves according to three key principles: order is emergent as opposed to predetermined, the system's history is irreversible, and the system's future is often unpredictable." In CAS, agents, events, and ideas bump into each other in somewhat unpredictable fashion, and change emerges from this dynamic interactive process. Because of this randomness, and the fact that complex dynamics can exhibit sensitivity to small perturbations (Lorenz, 1993), CAS are rather organic and unpredictable (Marion \& Uhl-Bien, 2001). Change in complex adaptive systems 
occur nonlinearly and in unexpected places, and, as Dooley (1996) observed, their history cannot be revisited (one cannot return a system to a previous state and rerun its trajectory).

Complexity science has identified a number of dynamics that characterize the formation and behaviors of CAS. For example, complexity science has found that interactive, adaptive agents tend to bond in that they adapt to one another's preferences and worldviews (Marion \& Uhl-Bien, 2001). From this, they form aggregates (i.e., clusters of interacting agents engaged in some measure of cooperative behavior). Mature social systems are comprised of a complex of hierarchically embedded, overlapping and interdependent aggregates, or CAS (Kauffman, 1993).

Complexity science has also found that the behaviors of interactive, interdependent agents and CAS are productive of emergent creativity and learning. Emergence refers to a nonlinear suddenness that characterizes change in complex systems (Marion, 1999; see also Plowman et al. in this edition). It derives from the collapse (or, more technically, dissipation) of built up tensions (Prigogine, 1997), sudden mergers (or divergences) of formerly separate CAS (Kauffman, 1993), or a cascade of changes through network connections (Bak, 1996). Creativity and learning occur when emergence forms a previously unknown solution to a problem or creates a new, unanticipated outcome (i.e., adaptive change).

CAS are unique and desirable in their ability to adapt rapidly and creatively to environmental changes. Complex systems enhance their capacity for adaptive response to environmental problems or internal demand by diversifying their behaviors or strategies (Holland, 1995; McKelvey, in press). Diversification, from the perspective of complexity science, is defined as increasing internal complexity (number and level of interdependent relationships, heterogeneity of skills and outlooks within CAS, number of CAS, and tension) to the point of, or exceeding, that of competitors or the environment (i.e., "requisite variety," Ashby, 1960 or "requisite complexity," McKelvey \& Boisot, 2003). Adaptive responses to environmental problems include counter-moves, altered or new strategies, learning and new knowledge, work-around changes, new allies, and new technologies. By increasing their complexity, CAS enhance their ability to process data (Lewin, 1992), solve problems (Levy, 1992), learn (Carley \& Hill, 2001; Levy, 1992), and change creatively (Marion, 1999).

Certain conditions will affect the capacity of CAS to emerge and function effectively in social systems. Agents must, for example, be capable of interacting with each other and with the environment. Agents must be interdependently related, meaning that the productive well being of one agent or aggregate is dependent on the productive well being of others. Moreover, they must experience tension to elaborate.

This capacity to rapidly explore solutions can be illustrated with a problem solving scenario called annealing, which is found in the evolution and simulation complexity literature (Carley, 1997; Carley \& Lee, 1998; Kauffman, 1993; Levy, 1992; Lewin, 1999). In this scenario, multiple agents struggle with localized effects created by a given environmental perturbations (or tension; this is called localized because an agent cannot usually perceive a problem as a whole nor do they typically have the capacity to deal with an environmental problem in its entirety). As these agents develop localized solutions, work-arounds, or related responses, they affect the behaviors of other interdependently related agents, who subsequently build on the original response to create higher-order responses. This process extends to broader network levels, to the fabric of interdependent agents, and to the CAS that define the system or subsystem. In this process interdependent agents and CAS experiment, change, combine strategies, and find loopholes in other strategies-and, occasionally, unexpected solutions emerge that address the problem at some level.

Information flows in the annealing process are not necessarily efficient and agents are not necessarily good information processors. Nor does annealing imply that structural adaptations are embraced as official strategy by upper echelon administrators or that the process finds perfect solutions. The annealing process is imperfect and somewhat messy - as Carley (1997) puts it, "it may not be possible for organizations of complex adaptive agents to locate the optimal form, [but] they can improve their performance by altering their structure" (p. 25). The annealing process (and other processes described in the complexity literature; e.g., McKelvey, in press; Prigogine, 1997) ${ }^{1}$ does, however, find solutions that individuals, regardless of their authority or expertise, could not find alone. Levy (1992), for example, describes bottom-up simulations that out-performed humans at finding solutions to mazes. Marion (1999) argued that technological and scientific advances inevitably emerge from a movement involving numerous individuals rather than from the isolated minds of individuals.

\footnotetext{
${ }^{1}$ There are other problem-solving approaches in the literature. Complex systems can, for example, respond to the accumulation of tension with phase transitions to new states (McKelvey, in press; Prigogine, 1997). All problem-solving strategies, however, are, in some fashion, driven by tension.
} 
In sum, complexity describes the interdependent interactions of agents within CAS, agents with CAS, and CAS with CAS. The primary unit of analysis in these interactive dynamics is, however, the CAS itself, and the behaviors of agents are always understood within the context of CAS. CAS are unique and desirable in that their heterogeneous, interactive, and interdependent structures allow them to quickly explore and consolidate solutions to environmental pressures. They require new models of leadership because problem solving is performed by appropriately structured social networks rather than by groups coordinated by centralized authorities. As Mumford \& Licuanan (2004) put it, effective leadership influence in conditions requiring creativity occurs through indirect mechanisms and through interaction.

Complexity is a science of mechanisms and interaction and is embedded in context. Mechanisms can be described as the dynamic behaviors that occur within a system such as a complex adaptive system. As defined by Hernes (1998), mechanisms are "a set of interacting parts - an assembly of elements producing an effect not inherent in any of them" (p. 74). They are "not so much about 'nuts and bolts' as about 'cogs and wheels' ...the "wheelwork" or agency by which an effect is produced" (Hernes, 1998, p. 74). Contexts are structural, organizational, ideational, and behavioral features - the ambiance of interactions among agents (people, ideas, etc.), hierarchical divisions, organizations, and environments - that influence the nature of mechanism dynamics. Examination of mechanisms and contexts will pry back the cover on leadership, so to speak, and help us to understand how and under what conditions certain outcomes occur.

To further explain this, we turn next to presentation of our framework for Complexity Leadership Theory. Complexity Leadership Theory is about setting up organizations to enable adaptive responses to challenges through network-based problem solving. It offers tools for knowledge-producing organizations and subsystems dealing with rapidly changing, complex problems. It also is useful for systems dealing with less complex problems but for whom creativity is desired.

\section{Complexity Leadership Theory}

Complexity Leadership Theory is a framework for leadership that enables thelearning, creative, and adaptive capacity of complex adaptive systems (CAS) in knowledge-producing organizations or organizational units. This framework seeks to foster CAS dynamics while at the same time enabling control structures appropriate for coordinating formal organizations and producing outcomes appropriate to the vision and mission of the system. It seeks to integrate complexity dynamics and bureaucracy, enabling and coordinating, exploration and exploitation, CAS and hierarchy, and informal emergence and top-down control.

Accomplishing this balance poses unique challenges for leadership, however: How can organizations enable and coordinate CAS dynamics and informal emergence (where appropriate) without suppressing their adaptive and creative capacity?

As described above, complex adaptive systems are intensely adaptive and innovative (Cilliers, 1998; Marion, 1999). CAS obtain the flexibility to adapt that has been attributed to loose coupling (Weick, 1976) and the capacity to coordinate from a more interdependent structure that is best described as moderately coupled (Kauffman, 1993; Marion, 1999). Moderately coupled interdependency (the actions of one agent are dependent on or limited by those of another) imposes restrictions on behavior. Thus flexibility and what might be called, auto-coordination, derives from informal but interdependent structures and activities (autocoordination emerges from the nature of system dynamics and is not imposed by authorities). Complexity theorists refer to such informal interactive interdependency as bottom-up behavior, defined as behaviors and changes that emerge spontaneously from the dynamics of neural-like networks. However, the term bottomup evokes images of hierarchy in organizational studies, so we will substitute the term informal emergence to describe these CAS dynamics in social systems (Plowman et al., 2007a; Plowman et al., 2007b; Plowman \& Duchon, in press; Lichtenstein et al., 2006).

Informal emergence and auto-coordination are seemingly incompatible with administrative coordination, but in reality it depends on the nature of the coordination. In complex adaptive systems, coordination comes from two sources: from informal emergent constraints imposed by interdependent relationships themselves (auto-coordination) and from constraints imposed by actions external to the informal dynamic, including environmental restrictions (Kauffman, 1993; Marion, 1999) and administrative controls (McKelvey, Marion, \& Uhl-Bien, 2003). Internal controls are imposed by a sense of common purpose that defines complex adaptive systems and from an inter-agent accountability that is inherent in interdependent systems (Marion \& Uhl-Bien, 2001; Marion \& Uhl-Bien, 2003; Schneider \& Somers, 2006). Hunt and Osborn evocatively describe internal coordination elsewhere in this special issue in their discussion of the Highlander tribes of New Zealand. 
External constraints and demands are imposed by environmental exigencies and relationships; indeed the core of Stuart Kauffman's (1993) influential descriptions of complex activities in biological evolution involves the inter-influence of multiple interacting species.

In organizational systems, administrators in formal positions of authority likewise influence complex adaptive systems by imposing external coordinating constraints and demands. Such constraints are valuable for (among other things) controlling costs, focusing efforts, allocating resources, and planning. However, authority imposed (top-down) coordination is not necessarily responsive to the potent dynamics of interdependent learning, creativity, and adaptability inherent in complex adaptive systems, and it tends to impose the understanding of a few on the "wisdom" of a neural network (Heckscher, 1994; McKelvey, in press). That is, top-down control (i.e., administrative leadership) can hamper the effective functioning of complex adaptive systems. This is particularly evident in systems with only top-down, hierarchical chains of authority, in systems with closely monitored, centralized goals, or in systems whose dominant ideology is authoritarian.

How, then, can organizations capitalize on the benefits of administrative coordination and of complex adaptive dynamics? Complexity Leadership Theory suggests that the role of managers should not be limited to aligning worker preferences with centralized organizational goals. Rather, managers, particularly under conditions of knowledge production, should act to enable informal emergence and to coordinate the contexts within which it occurs.

\section{A framework for Complexity Leadership Theory}

This leads us to our overarching framework for Complexity Leadership Theory. This framework envisions three leadership functions that we will refer to as adaptive, administrative, and enabling. Adaptive leadership refers to adaptive, creative, and learning actions that emerge from the interactions of CAS as they strive to adjust to tension (e.g., constraints or perturbations). Adaptive activity can occur in a boardroom or in workgroups of line workers; adaptive leadership is an informal emergent dynamic that occurs among interactive agents (CAS) and is not an act of authority. Administrative leadership refers to the actions of individuals and groups in formal managerial roles who plan and coordinate activities to accomplish organizationally-prescribed outcomes in an efficient and effective manner. Administrative leadership (among other things) structures tasks, engages in planning, builds vision, allocates resources to achieve goals, manages crises (Mumford, et al., in press) and conflicts, and manages organizational strategy (see Yukl, 2005). Administrative leadership focuses on alignment and control and is represented by the hierarchical and bureaucratic functions of the organization. Enabling leadership works to catalyze the conditions in which adaptive leadership can thrive and to manage the entanglement (described below) between the bureaucratic (administrative leadership) and emergent (adaptive leadership) functions of the organization. Managing entanglement involves two roles: (1) creating appropriate organizational conditions (or enabling conditions) to foster effective adaptive leadership in places where innovation and adaptability are needed, and (2) facilitating the flow of knowledge and creativity from adaptive structures into administrative structures. Enabling leadership occurs at all levels of the organization (as well as within the adaptive dynamic), but the nature of this role will vary by hierarchical level and position.

In Complexity Leadership Theory, these three leadership functions are intertwined in a manner that we refer to as entanglement (Kontopoulos, 1993). Entanglement describes a dynamic relationship between the formal top-down, administrative forces (i.e., bureaucracy) and the informal, complexly adaptive emergent forces (i.e., CAS) of social systems. In organizations, administrative and adaptive leadership interact and may help or oppose one another. Administrative leadership can function in conjunction with adaptive leadership or can thwart it with overly authoritarian or bureaucratic control structures. Adaptive leadership can work to augment the strategic needs of administrative leadership, it can rebel against it, or it can act independently of administrative leadership. The enabling leadership function helps to ameliorate these problems; it serves primarily to enable effective adaptive leadership, but to accomplish this it must tailor the behaviors of administrative and adaptive leadership so that they function in tandem with one another.

In formal organizations, one cannot disentangle bureaucracy from CAS. Earlier we stated that CAS are the basic unit of analysis in a complex system. However, as all organizations are bureaucracies (there are no such things as "post-bureaucratic" organizations, see Hales, 2002), CAS necessarily interact with formal bureaucratic structures in organizations. Moreover, there are times and conditions in which rationalized structure and coordination (e.g., hierarchical authority) need to be emphasized in subunits (e.g., when the environment is stable and the system seeks to enhance profits). At other times or conditions, firm may prefer to emphasize complexity and CAS (e.g., when environments are volatile or the competition's flexibility is threatening). 
A role of enabling leadership at the strategic level (Jaques, 1989), then, is to manage the coordination rhythms, or oscillations, between relative importance of top-down, hierarchical dynamics and emergent complex adaptive systems (Thomas, et al., 2005). Ultimately, neither can be separated from the other in knowledge-producing organizations, for such firms must nurture both creativity and exploitation to be fit.

Based on this, we can summarize the main points we have developed thus far as follows:

- Complexity Leadership Theory provides an overarching framework that describes administrative leadership, adaptive leadership and enabling leadership; it provides for entanglement among the three leadership roles and, in particular, between CAS and bureaucracy.

- Adaptive leadership is an emergent, interactive dynamic that is the primary source by which adaptive outcomes are produced in a firm. Administrative leadership is the actions of individuals and groups in formal managerial roles who plan and coordinate organizational activities (the bureaucratic function). Enabling leadership serves to enable (catalyze) adaptive dynamics and help manage the entanglement between administrative and adaptive leadership (by fostering enabling conditions and managing the innovation-to-organization interface). These roles are entangled within and across people and actions.

We now expand the elements introduced by Complexity Leadership Theory, beginning with administrative leadership and then moving into the adaptive and enabling roles.

\subsection{Administrative leadership}

Administrative leadership refers to the actions of individuals in formal managerial roles who plan and coordinate organizational activities (e.g., the bureaucratic function). Administrative leaders (among other things) structure tasks, engage in planning, build vision, acquire resources to achieve goals (Dougherty \& Hardy, 1996; Shalley \& Gilson, 2004), manage crises (Mumford \& Licuanan, 2004) and personal conflicts (Jehn, 1997), and manage organizational strategy. The nature of this administrative leadership varies within the hierarchical level of the system. Administrators at Jaques' (1989) strategic level engage in planning, coordination, resource acquisition (Osborn \& Hunt, 2007), and structuring conditions related to strategy (Marion \& Uhl-Bien, 2007). At Jaques' organizational level, administrators implement more focused planning and coordination of creative operations, manage resource allocation, and structure conditions within which adaptive leadership occurs.

Administrative leadership is a top-down function based on authority and position, thus it possess the power to make decisions for the organization. However, within the structure described by Complexity Leadership Theory, administrative leadership is advised to exercise its authority with consideration of the firm's need for creativity, learning, and adaptability (i.e., adaptive leadership), for its actions can have significant impact on these dynamics. A decision, for example, to exercise profitable efficiency in a volatile environment could deprive a firm of much needed adaptive capacity.

\subsection{Adaptive leadership}

Adaptive leadership is an emergent, interactive dynamic that produces adaptive outcomes in a social system. It is a collaborative change movement that emerges nonlinearly from interactive exchanges, or, more specifically, from the "spaces between" agents (cf. Bradbury \& Lichtenstein, 2000; Drath, 2001; Lichtenstein et al., 2006). That is, it originates in struggles among agents and groups over conflicting needs, ideas, or preferences; it results in movements, alliances of people, ideas, or technologies, and cooperative efforts. Adaptive leadership is a complex dynamic rather than a person (although people are, importantly, involved); we label it leadership because it is $a$, and, arguably, the, proximal source of change in an organization.

Adaptive leadership emerges from asymmetrical interaction (the notion of complexity and asymmetry is developed by Cilliers, 1998). We propose two types of asymmetry: that related to authority and that related to preferences (which include differences in knowledge, skills, beliefs, etc.). If an interaction is largely one-sided and authority-based, then the leadership event can be labeled as top-down. If authority asymmetry is less onesided and more preference oriented, then the leadership event is more likely based on interactive dynamics driven by differences in preferences. 
Struggles over asymmetrical preference differences foster adaptive change outcomes (thus the earlier statement that change emerges from the spaces between agents). Adaptive change is produced by the clash of existing but (seemingly) incompatible ideas, knowledge, and technologies; it takes the form of new knowledge and creative ideas, learning, or adaptation. A familiar form of this change occurs when two interdependent individuals who are debating conflicting perceptions of a given issue suddenly, and perhaps simultaneously, generate a new understanding of that issue - this can be considered an "aha" moment. The "aha" is a nonlinear product of a combination of the original perceptions, of the discarding of untenable arguments and the fusion of what is tenable, or perhaps of the rejection of original ideas as untenable and the creation of a totally new idea. It represents a process of seeing beyond original assumptions to something not bounded by those assumptions. Moreover, it cannot be claimed by any one individual, but rather is a product of the interactions among individuals (i.e., it is produced in the "spaces between"; Bradbury \& Lichtenstein, 2000).

Adaptive leadership is recognized as such when it has significance and impact-significance is the potential usefulness of new, creative knowledge or adaptive ideas and impact refers to the degree to which other agents external to the generative set embrace and use the new knowledge or idea. The significance of an adaptive moment is related to the expertise of the agents who generate that moment (Mumford et al., 2002; Weisburg, 1999) and to their capacity for creative thinking (Mumford, et al., 2003). Expertise and creativity are not necessarily co-resident in an adaptive event, of course. Quite obviously, creative individuals without training in physics are not going to advance that field, but neither are, one might argue, two physicists who are unable or unwilling to break out of their paradigmatic assumptions. Complex systems depend on the former (expertise) and stimulate the latter (creativity).

Impact can be independent of significance because impact is influenced by (among other things) the authority and reputation of the agents who generated the idea, the degree to which an idea captures the imagination or to which its implications are understood, or whether the idea can generate enough support to exert an impact (see Arthur, 1989, for discussion). Thus an insignificant idea can have considerable circulation.

Complexity Leadership Theory describes conditions in which adaptive dynamics emerge and generate creative and adaptive knowledge that exhibits sufficient significance and impact to create change. Adaptive leadership is not an act of an individual, but rather a dynamic of interdependent agents (i.e., CAS). To exhibit significance and impact, adaptive leadership must be embedded in an appropriately structured, neural-like network of CAS and agents (within the context of CAS; i.e., network dynamics) and exhibit significance and impact that generate change in the social system.

\subsubsection{Network dynamics}

Network dynamics refer to the contexts and mechanisms that enable adaptive leadership. As defined above, context is the interactive ambiance within which complex dynamics occur, and mechanisms are the dynamic patterns of behavior that produce complex outcomes. In interactive and interdependent networks, adaptive ideas, whether small or large, emerge and interact in much the same way that pairs or groups of agents interact. The contexts that shape those ideas include networks of interaction, complex patterns of conflicting constraints, patterns of tension, interdependent relationships, rules of action, direct and indirect feedback loops, and rapidly changing environmental demands. The mechanisms that emerge include resonance (i.e., correlated action; see below) and aggregation of ideas, catalytic behaviors (behaviors that speed or enable certain activities; Kauffman, 1993), generation of both dynamically stable and unstable behaviors, dissipation of built up tension as phase transitions (Prigogine, 1997), nonlinear change, information flow and pattern formation, and accreting nodes ${ }^{2}$ (ideas that rapidly expand in importance and which accrete related ideas) (see Figure 1). In complex networks, ideas emerge, combine, diverge, become extinct, conflict with one another, adapt and change, and increase in complexity. The primary outputs of this complex dynamic are adaptability, creativity, and learning.

Adaptive leadership emerges within this complex milieu of contexts and mechanisms - it exists in complex network contexts and produces (and is produced by) complex mechanisms. There are two interactive and interdependent levels of pertinent activity:(1) the interaction of agents and CAS that produceideas and knowledge, and (2) the interaction of the ideas and knowledge to produce even more complex ideas and knowledge. Loosely adapting Cohen et al.'s (1972) garbage can metaphor, we can envision this as a complex garbage can in which

${ }^{2}$ The notion of accreting nodes is derived from related work in fractal geometry; see, for example, Mandelbrot, 1983. 
The Emergence Dynamic

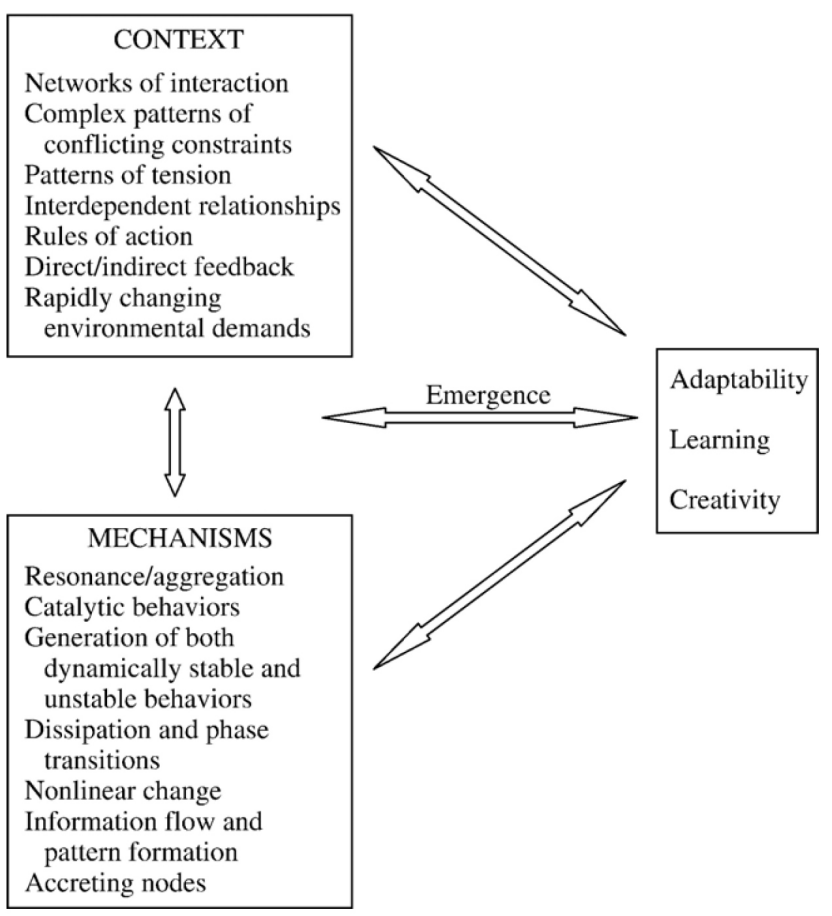

Figure 1. The emergence dynamic.

agents and CAS and contexts and mechanisms and ideas and knowledge swirl. The end result is emergent creativity, learning, and adaptability at all levels of the system and at multiple scales of importance.

\subsubsection{Emergence}

Earlier we defined the complex change process in terms of "spaces between" and struggles over diverse ideas. We now define it more precisely in terms of emergence. Emergence involves two, interdependent mechanisms: (1) the reformulation of existing elements to produce outcomes that are qualitatively different from the original elements; and (2) self-organization. Reformulation competes with theories of natural selection or human intelligence as a source of unique change (but, importantly, it does not preempt the involvement of other such dynamics; see Kauffman, 1993, for example). Reformulation is defined as the expansion, parsing, amplification, transformation, and combination of multiple interacting, often conflicting, elements under conditions of tension and asymmetrical information. It is produced by complex (as opposed to complicated) interactive mechanisms within appropriately structured contexts; thus reformulation is intimately linked to the random nature of interaction in complex networks and outcomes can be unpredictable and nonlinear. The essence of the original elements is transformed in a manner that gives new meaning or interpretation to the resulting outcome. That is, the system changes in a fundamental way.

Wikipedia defines self-organization as a process in which the "internal organization of a system, normally an open system, increases in complexity without being guided or managed by an outside source" (Wikipedia, n.d.) This phenomenon is well documented in physics, biology, and the social sciences (see the above Wikipedia entry on self-organization for examples). We modify this definition for leadership studies, defining it in terms of resonating reformulation events (Marion \& Uhl-Bien, 2001). Resonance is defined as acting in concert; it refers more specifically to situations in which the behaviors of two or more agents are interdependent. Thus clusters of cars speeding down a highway are resonating together. Self-organization, then, is a movement in which different reformulation activities find common cause. The modern terrorist movement, for example, is a selforganized event (Marion \& Uhl-Bien, 2003). Importantly, human volition (e.g., managerial coordination) can play important roles in our definition of self-organization; however, volition is not necessarily determinative of self-organizing behaviors but is rather an actor in this dynamic. 
We now formally define adaptive leadership:

Definition: Adaptive leadership is defined as emergent change behaviors under conditions of interaction, interdependence, asymmetrical information, complex network dynamics, and tension. Adaptive leadership manifests in CAS and interactions among agents rather than in individuals, and is recognizable when it has significance and impact.

\subsubsection{Multi-level adaptive leadership}

CAS occur in all hierarchical levels of an organization. The emergent outcomes and the significance and impact of adaptive behaviors differ across hierarchical levels of course (Boal et al., 1992; Hunt \& Ropo, 1995; Phillips \& Hunt, 1992). Broadly addressed, the adaptive outputs for the upper level of a hierarchy (what Jaques, 1989, called, the strategic level) relate largely to emergent planning, resource acquisition, and strategic relationships with the environment (for discussion, see Marion \& Uhl-Bien, 2007; see also Child \& McGrath, 2001, for a useful discussion of interdependency among organizations). Adaptive outputs for the middle hierarchical levels (middle management, or what Jaques, 1989, called, the organizational level) relate to emergence of focused planning, resource allocation, etc. That for the lower levels (Jaques' production level) relates to development of the core products of the organization; for knowledge-producing organizations, this includes knowledge development, innovation, and adaptation (Osborn \& Hunt, 2007-this issue, provide an extensive discussion of complexity and the levels perspective).

\subsection{Enabling leadership}

The role of enabling leadership in the CLT framework is to directly foster and maneuver the conditions (e.g., context) that catalyze adaptive leadership and allow for emergence. Middle managers (Jaques, 1989) are often in a position to engage in enabling behaviors because of their access to resources and their direct involvement in the boundary conditions for the system's production level (see Osborn \& Hunt, 2007). However, enabling leadership can be found anywhere. Its role seemingly overlaps, at times, that of administrative leadership in that it may be performed by agents acting in more managerial capacities. Moreover, a single agent or aggregate can perform either adaptive or enabling roles by merely changing hats as needed.

The roles of enabling leadership can be summarized as follows:

- Enabling leadership enables effective CAS dynamics by fostering enabling conditions that catalyze adaptive leadership and allow for emergence.

- Enabling leadership manages the entanglement between administrative and adaptive leadership; this includes (1) managing the organizational conditions in which adaptive leadership exists, and (2) helping disseminate innovative products of adaptive leadership upward and through the formal managerial system (i.e., the innovation-to-organization interface, Dougherty \& Hardy, 1996).

\subsubsection{Enable conditions that catalyze adaptive leadership}

One function of enabling leadership is to catalyze CAS dynamics that promote adaptive leadership. Catalyzing refers to activities that bring together the enabling conditions (mechanisms and contexts) necessary for adaptive leadership to emerge. As described earlier, complex networks conducive to adaptive leadership are (among other things) interactive, moderately interdependent, and infused with tension. Enabling leadership, then, fosters complex networks by (1) fostering interaction, (2) fostering interdependency, and (3) injecting adaptive tension to help motivate and coordinate the interactive dynamic.

\footnotetext{
3.3.1.1. Interaction Effective network conditions are catalyzed first by interaction. Interaction produces the network of linkages across which information flows and connects. Enabling leaders cannot create the sophisticated dynamic linkages that characterize complex networks, nor can they accurately pre-calculate what constitutes the right amount of coupling. Rather, such networks are self-organizing. They can, however, create the general structure of complex networks and the conditions in which sophisticated networks can evolve. For example, from an organizational level (Jaques, 1989), enabling leadership can foster interaction through such strategies as open architecture work places, self-selected work groups, electronic work groups (email, etc.), and by management-induced scheduling or rules structuring.
} 
Moreover, the interactive imperative is not bounded to the immediate work group, but extends to interactions with other groups (CAS) and with the environment. Interaction with other CAS fosters crossgroup initiatives, possible aggregation of different ideas into larger ideas, a degree of coordination across efforts, and the importation of information that may inform the target work group.

Further, at Jaques' (1989) strategic level, enabling leadership helps foster interactions of organizational CAS with environmental dynamics. This serves at least two purposes: it enables importation of fresh information into the creative dynamic (Boisot, 1998), and it broadens the organization's capacity to adapt to environmental changes and conditions beyond the adaptive capacity of strategic leadership acting alone. Marion \& Uhl-Bien (2007) propose that organizational adaptability should even be a significant element of strategic planning because of its capability to adapt quickly and competently to environmental changes; a particularly potent example is evident in the adaptive strategies of terrorist networks (see Marion \& Uhl-Bien, 2003). For a more extensive discussion of complexity and strategic leadership, see the Boal \& Schultz (2007).

Individual agents in adaptive networks can act in an enabling role by adopting behaviors that enhance their interactive contributions. For example, they can enlarge their personal networks to increase the amount of access and network resources they can bring to the table. Moreover, they can contribute to the flow of information across CAS by keeping themselves informed and knowledgeable on issues important to the firm and their field and by framing issues appropriate to the perspectives of the others with whom they are interacting. They can also monitor the environment (e.g., political, economic, social, national, international, technological) to understand the nature of the forces that are influencing the adaptive dynamic.

3.3.1.2. Interdependency Interaction alone is insufficient for complex functioning; the agents in a system must also be interdependent. While interaction permits the movement and dynamic interplay of information, interdependency creates pressure to act on information. Interdependency's potency derives from naturally occurring (emergent) networks of conflicting constraints. Conflicting constraints manifest when the wellbeing of one agent is inversely dependent on the well-being of another, or when the information broadcasted by one agent is incompatible with that broadcasted by another agent. Such constraints pressure agents to adjust their actions and to elaborate their information.

At the organizational level (Jaques, 1989) there are a number of ways to manage conditions that catalyze interdependency mechanisms. One useful tool for promoting interdependency is to allow measured autonomy for informal behavior (see also Shalley \& Gilson, 2004). Autonomy permits conflicting constraints to emerge and enables agents to work through those constraints without interference from formal authorities. Nordstrom illustrates this approach in a statement in their employee handbook:

We also encourage you to present your own ideas. Your buyers have a great deal of autonomy, and are encouraged to seek out and promote new fashion directions at all times ... and we encourage you to share your concerns, suggestions and ideas. (Pfeffer, 2005, p. 99)

A major function of leaders has historically been to solve problems, to intervene when dilemmas arise or when individuals differ on task-related activities. Such action, however, can stifle interdependency and limit adaptive mechanisms. Complexity Leadership Theory proposes circumspection by administrative leaders in such matters, to resist the temptation to create an atmosphere in which workers bring their work problems to management (see Alvesson \& Sveningsson, 2003). Enabling leaders fosters such circumspection by mediating this issue with administrative leaders who are overly involved, by stifling one's own desire in administrative roles to act in this way, or even by implementing policy regarding the resolution of problems and task conflicts (see, for example, Snyder's, 1988, description of such implementation).

At the strategic level enabling leaders can foster interdependency with rules - not limiting bureaucratic rules but rules or conditions that apply pressure to coordinate (Eisenhardt, 1989; McKelvey et al., 2003). Microsoft's $\mathrm{s}^{\mathrm{TM}}$ strategy for developing software, for example, is built on interactive work groups and ruleenabled interdependencies (Cusumano, 2001). Programmers operate independently and in small groups, but are periodically required to run their code against the code of other programmers. If there are problems, the team must repair the incompatibility before moving on. Microsoft calls this "sync and stabilize." The process imposes interdependency that can create cascading changes and elaboration in Microsoft's software. Microsoft gains the benefit of flexibility, adaptability, speed, and innovation while maintaining coordinated action. 
At the individual level, agents engaging in enabling leadership recognize the importance of interdependency and they can function to foster coordinated efforts. Enabling agents refine or realign their information relative to the information of the other agents (Kauffman, 1993; Marion \& Uhl-Bien, 2001) in ways that contribute to co-evolution or co-elaborating of ideas and information such that new, sometimes surprising information can emerge (Kauffman, 1993).

3.3.1.3. Tension Finally, since tension creates an imperative to act and to elaborate strategy, information, and adaptability, enabling leadership also works to foster tension. Internal tension can be enhanced by heterogeneity, a stimulus of interdependency and conflicting constraints. Heterogeneity refers to differences among agents in such things as skills, preferences, and outlooks (McKelvey, in press; Schilling \& Steensma, 2001). When couched within a context of interdependency, heterogeneity pressures agents to adapt to their differences. At the upper echelon and organizational levels, enabling leadership promotes heterogeneity by (among other things) building an atmosphere in which such diversity is respected, with considered hiring practices, and by structuring work groups to enable interaction of diverse ideas. Enabling leadership also fosters internal tension by enabling an atmosphere that tolerates dissent and divergent perspectives on problems, one in which personnel are charged with resolving their differences and finding solutions to their problems (cf. Heifetz \& Laurie, 2001).

Enabling leadership not only fosters internal tension, it judiciously injects tension as well-tension that derives externally in that it is not a natural function of informal dynamics. Upper- and mid-level enabling leaders inject tension with managerial pressures or challenges, by distributing resources in a manner that supports creative movements, and by creating demands for results. Enabling leaders can impose tension by dropping "seeds of emergence" (Marion \& Uhl-Bien, 2001; McKelvey et al., 1999), or perturbations that have the potential of fostering learning and creativity. Such "seeds" include ideas, information, judiciously placed resources, new people, and the capacity to access unspecified resources (i.e., gateways that permit exploration; access to the internet is an obvious example). Seeds are intended to stimulate the networked system, and their impact may be unpredictable.

At the individual level, agents can engage in enabling leadership by recognizing the creative value of tension and using it to foster productive discussions and interaction. They would not look to authority for answers, but rather commit to engaging in the process of adaptive problem solving. Enabling agents recognize the difference between task (or ideational) conflict (which can produce creative outcomes; Jehn, 1997), and interpersonal conflict (which is disruptive to social dynamics) and work to promote productive, task conflicts (Heifetz, 1994; Jehn, 1997; Lencioni, 2002). They contribute ideas and opinions, they play devil's advocate, and they address the "elephants on the table" that others try to ignore (Parks, 2005). They also recognize when a group is bogged down by consensus (Lencioni, 2002) that comes from lack of diversity, and expose the group to heterogeneous perspectives, bringing other people and ideas into the dynamic as necessary.

Enabling leadership can also emerge from within the adaptive function. Schreiber (2006), in a study of complexity leadership and risk factors, identified several interesting enabling dynamics in work groups (measurements from these observations were used in a follow-up multi-agent based simulation). Certain agents emerged, for example, who tended to induce interactions and establish interdependencies. Others were boundary spanners, or "agent[s] who most likely connect ... to otherwise disjoint groups" (p. 136). Some agents emerged who were "likely to have the most interactions and to learn more knowledge" (p. 136). There were also agents "who can most quickly communicate to the organization at large" (p. 136). Lastly, some agents were "most likely to communicate new knowledge" (p. 136). Such agent-roles represent nodes in a neural network of agents (see, for example, Carley \& Ren, 2001) and serve to enable (and operationalize) interaction, interdependency, and learning within CAS.

\subsubsection{Managing the entanglement between adaptive and administrative structures}

A second function of the enabling leadership role is to manage the entanglement between CAS dynamics and formal administrative systems and structures. This involves using authority (where applicable), access to resources, and influence to keep the formal and informal organizational systems working in tandem rather than counter to one another (Dougherty, 1996). In this function, enabling leaders:

1) work to prevent administrative leaders from stifling or suppressing beneficial interactive dynamics and foster adaptive dynamics that are consistent with the strategy and mission of the organization (the administrative-adaptive interface); and 
2) facilitate the integration of creative outcomes into the formal system (i.e., the innovation-to-organization interface, Dougherty \& Hardy, 1996).

3.3.2.1. Managing the administrative-adaptive interface Regarding the first of these roles, enabling leaders help protect the CAS from external politics and top-down preferences. They serve to influence the policies and decisions of administrative leadership, including planning and resource allocation, to accommodate the needs of adaptive structures (Dougherty \& Hardy, 1996). They also help align organizational strategy to the needs of CAS dynamics and convince administrative leadership when CAS dynamics are important for organizational strategy (Marion \& Uhl-Bien, 2007).

Managing the conditions for adaptive leadership requires a different focus on planning and resource allocation. With regard to planning, Mumford et al. (in press) note a lack of consensus in the leadership literature about whether creativity is enabled or hampered by administrative planning (Bluedorn et al., 1994; Finkelstein \& Hambrick, 1996). Some scholars argue that planning provides the resources and structure that creative initiatives require while others argue that administrators cannot anticipate and plan the directions in which creative dynamics will flow (Mumford et al., in press). Complexity Leadership Theory (CLT) has similar concerns about planning. On the one hand, emergence is the product of informal adaptive behavior that would be hampered by top-down restrictions (Krause, 2004). On the other hand, the need to focus creative behaviors is legitimate; indeed unrestrained adaptive behavior would be expensive to support and could compromise rather that enhance the organization's strategic mission.

Framing the question for Complexity Leadership Theory, we ask: Does planning enable or inhibit nonlinear emergence? Our short answer is: It depends on the nature of the plan. Planning for creativity must deal with significant uncertainties, including the fact that creativity by definition involves development of ideas that are currently unknowable (Popper, 1986), changing future environmental uncertainties, and uncertainty about whether creative ideas will become viable market solutions. (Mumford et al., in press) and (Mumford et al., 2002)) propose evolving and flexible plans to deal with such uncertainties. They divide their planning model into five stages: 1) scanning, 2) template planning, 3) plan development, 4) forecasting, and 5) plan execution. These stages can be summarized as idea identification (scanning and template planning), plan development (including forecasting), and plan execution. Mumford et al. (2002) argue that plans should be adapted to the needs of each stage and that planning within these stages should be a continuous process in order to adjust for changes and unknowns that are certain to arise. Mumford et al. (in press) further argue that R\&D programs must be understood in the long term and that leaders of R\&D are managers of systemic dynamics rather than of day-to-day details.

Mumford et al. (in press) propose that organizational plans should impose limits that assure creative emergence is consistent with the core competencies (or themes) of the system. This focuses creativity around practical constraints without unduly dampening the creative spirit. We further propose that planners separate the creative process from the structure in which it occurs: The creative process itself (e.g., adaptive behaviors) should not be unduly managed or constrained by administrative planning and coordination; however that process should be couched within a larger planning structure similar to that proposed (above) by Mumford et al.

Therefore, our framework proposes that enabling leadership, in general, assumes a systemic relationship with complex dynamics, one in which the responsibility is to provide the framework and conditions within which enabling and adaptive leadership function. At Jaques' (1989) strategic level enabling leaders plan a trajectory for the adaptive process and have a long-term outlook (Marion \& Uhl-Bien, 2007). Enabling leaders at Jaques' (1989) organizational level, in contrast, plan the context surrounding work; their function is more short-term than that of strategic leaders and is focused on the given stage of a plan at any given time.

With regard to resources, the literature on creativity has noted the importance of increasing the availability of information resources (Reiter-Palmon \& Illies, 2004). Similarly, complex adaptive systems depend on flows of information resources, and when such flows are hindered, they do not operate effectively. Therefore, enabling leaders provide resources that enhance access to information (e.g., access to electronic databases). They coordinate acquisition and allocation of resources (money, supplies, information, personnel, etc.) that support creative, learning, and adaptive behaviors of CAS. Bonabeau \& Meyer (2001) add that leaders can enhance the adaptive process by allowing physical resources (e.g., money, supplies, etc.) to follow emergent ideas (see also Dougherty \& Hardy, 1996). This fosters motivation and creates tension related to scarce resources. Since personnel are resources, and diversity of personnel skills and preferences are important to the creative and adaptive functions of CAS, enabling leaders also promote diversity in hiring practices and policy actions. 
Enabling leadership manages conditions consistent with the strategy and mission of the organization by articulating the mission of a project (e.g., Kennedy's mission to put Americans on the moon by 1970; see, for example, Jaussi \& Dionne, 2003). Complexity Leadership Theory adds (as does Mumford et al., in press), however, that such missions should not be so specific that they restrict the creative process. They should be sufficiently flexible to change with changing conditions.

Strategy and mission consistency is fostered by discouraging non-useful adaptations. Adaptive leadership is, by design, unpredictable, and its emergent activities can evolve in directions that are contrary to the strategic mission of the organization. Enabling leaders help realignment of non-useful adaptations by (for example) periodically evaluating adaptive outputs for a given stage of development relative to organizational mission-themes (see Mumford et al., in press), by clearly articulating the mission (described above), or by offering technical support that is consistent with organizational themes.

Enabling leaders promote behavior that advances strategic goals by dealing with crises that threaten to derail adaptive functions (Mumford et al., in press); by protecting the creative process from forces (e.g., boards or directors, other administrators, environmental pressures) that would limit the capacity of the organization or its subsystems to engage in creativity, learning, and adaptation; and by structuring conditions such as missions, physical conditions, crises, personal conflicts, and external threats in ways that support creative adaptive behaviors.

3.3.2.2. Managing the innovation-to-organization interface In the second role identified above, enabling leaders help in the innovation-to-organization interface. Howell \& Boies (2004) refer to this as championing. They argue, describing creative ideas, that:

To overcome the social and political pressures imposed by an organization and convert them to its advantage, champions demonstrate personal commitment to the idea, promote the idea ... through informal networks, and willingly risk their position and reputation to ensure its success... [They] establish ... and maintain... contact with top management, to keep them informed and enthusiastic about the project. ... [A] new venture idea require[s] a champion to exert social and political effort to galvanize support for the concept. (p. 124)

As noted by Dougherty \& Hardy (1996), formal organizational systems are often not structured to foster internal dissemination of innovation - rather, they tend to inhibit it. Because formal structures present obstacles for innovation-to-organization transference, power is needed to facilitate, orchestrate, and share innovative ideas and outcomes throughout the organization. "Unless product innovation has an explicit, organizationwide power basis, there is no generative force, no energy, for developing new products continuously and weaving them into ongoing functioning" (Dougherty \& Hardy, 1996, p.1146). They suggest that organizations adopt a "pro-innovation" approach by moving beyond reliance on networks of personal power (a focus on individuals) and toward an organization-system base of power. Such a system would foster processes that "link the right people" and "emphasize the right criteria," as well as "allow resources to begin to flow to the right places" (Dougherty \& Hardy, 1996, p.1149). Enabling leaders can play an integral role in helping design and protect such a "pro-innovation" organizational system.

Enabling leadership also works with adaptive and administrative leadership to decide which creative outputs of the adaptive subsystem are the most appropriate to move forward into the broader bureaucratic structure. In conducting this function, Mumford et al. (in press) caution administrators to avoid assessing the creative output itself and to instead focus on assessing the degree to which activities are accomplishing the functions of the given stage of development. "Evaluation," they argue, "should be viewed as a developmental exercise with multiple cycles of evaluation and revision occurring in any stage before planning progresses to the next stage" (in press). Therefore, enabling leadership helps coordinate the interface between adaptive and administrative leadership by working for policies and strategies that enable complex dynamics and by adopting a "pro-innovation" environment that facilitates innovation-to-organization transference.

\subsubsection{Summary}

Complexity Leadership Theory (CLT), then, is a framework for studying emergent leadership dynamics in relationship to bureaucratic superstructures. CLT identifies three types of leadership, adaptive, enabling, and administrative, and proposes that they differ according to where they occur in the larger organizational hierarchy. A basic unit of analysis of CLT is complex adaptive systems (or CAS), which exist throughout 
the organization and are entangled with the bureaucratic functions such that they cannot be separated. CLT proposes that CAS, when functioning appropriately, provide an adaptive capability for the organization, and that bureaucracy provides an orienting and coordinating structure. A key role of enabling leadership is to effectively manage the entanglement between administrative and adaptive structures and behaviors in a manner that enhances the overall flexibility and effectiveness of the organization (Marion \& Uhl-Bien, 2007). By focusing on emergent leadership dynamics, CLT implies that leadership only exists in, and is a function of, interaction; despite this, there are roles for individual leaders in interacting with (i.e., enabling) this dynamic.

\section{Conclusion}

As described by Rost (1991), leadership study has been bogged down in the periphery and content of leadership, and what is needed is "a new understanding of what leadership is, in a post-industrial school of leadership" (Rost, 1991, p. 181). In the present article we attempt to move toward such an understanding by developing a model of leadership based in complexity science. Complexity science is a modern "normal" science, the assumptions of which fit the dynamics of social, managerial, and organizational behavior in high velocity, knowledge-type environments (Henrickson \& McKelvey, 2002). Complexity science allows us to develop leadership perspectives that extend beyond bureaucratic assumptions to add a view of leadership as a complex interactive dynamic through which adaptive outcomes emerge. This new perspective, which we label Complexity Leadership Theory, recognizes that leadership is too complex to be described as only the act of an individual or individuals; rather, it is a complex interplay of many interacting forces.

Complexity Leadership Theory focuses primarily on the complex interactive dynamics of CAS and addresses how individuals interact with this dynamic to enable adaptive outcomes. CAS are the basic unit of analysis in Complexity Leadership Theory. CAS are comprised of agents, however, and their roles in the CAS dynamic is important. Further, individuals (particularly those in positions of authority) can influence the CAS function and are likewise of interest in Complexity Leadership Theory.

Research on CAS in Complexity Leadership Theory should examine the dynamic (i.e., changing, interactive, temporal), informal interactive patterns that exist in and among organizational systems. This generates interesting questions for leadership research. For example, what patterns of behavior (what Allen, 2001, calls, structural attractors) do organizational CAS gravitate to and are there "patterns to those patterns" across systems? What is the specific generative nature of asymmetry and how does it function within a network dynamic? What enabling functions emerge from a complex network dynamic (such as those found by Schreiber, 2006)? What psychosocial dynamic occurs in the "spaces between agents" emergent dynamic? What are the mechanisms by which a social system moves from one stable pattern to another? What contexts are conducive to given patterns of interaction and how do enabling and administrative leaders help foster or stifle those contexts?

A complexity leadership approach adds to leadership research a consideration of the mechanisms and contexts by which change occurs and systems elaborate rather than a predominant focus on variables. To understand mechanisms requires methodology that is capable of analyzing the interactions of multiple agents over a period of time (see Hazy, 2007). Developing an understanding of the mechanisms that underlie Complexity Leadership Theory and the conditions in which such mechanisms will emerge is critical as we move our theorizing forward into embedded context approaches in leadership (Osborn et al., 2002). There can be any number of mechanisms underlying the Complexity Leadership Theory function. In this article we focus on such mechanisms as interaction among heterogeneous agents, annealing, requisite variety, information flows, catalyzing activities, and nonlinear emergence.

Research regarding complexity dynamics needs to capture the nature of mechanisms, which are nonlinearly changeable, unpredictable in the long term (and sometimes in the short term), temporally based, and interactively and causally complex. We suggest two methodological strategies for doing this. First, qualitative procedures allow temporal evaluations and have been used in complexity studies (Bradbury \& Lichtenstein, 2000). Second, various computer modeling procedures have been utilized for complexity research (see Hazy, 2007), the most common being agent based modeling (Carley \& Svoboda, 1996) and system dynamic modeling (Sterman, 1994).

In agent based modeling, individual, computerized agents are programmed to interact according to certain defined rules of sociological and organizational engagement (Carley \& Svoboda, 1996). Systems dynamics model the interaction of more global variables and dynamics with equations that define their relationships. In either case, a common approach is to measure certain characteristics of a social group (e.g., organizational 
work groups) and to use those data as initial conditions in a simulation. This obviates the need to make detailed, on-site observations across time and permits the researcher to experiment with "what-if" scenarios (e.g., what if hierarchical centralization is increased). Jim Hazy has provided an excellent review of simulation procedures elsewhere in this special issue [of The Leadership Quarterly] (Hazy, 2007); see also Guastello's article (2007) for a statistics-based, research strategy, and Plowman et al. (2007a) and Plowman et al. (2007b) for a qualitative methodology.

In sum, in this article we develop and outline key elements of Complexity Leadership Theory. We argue that while the Knowledge Era calls for a new leadership paradigm, much of leadership theory still promotes an approach aimed at incentivizing workers to follow vision-led, top-down control by CEOs (Bennis, 1996; Zaccaro \& Klimoski, 2001). Though this approach fits recent trends toward performance management and accountability, it can stifle a firm's innovation and fitness (Marion \& Uhl-Bien, 2001; Schneider \& Somers, 2006). We propose that Complexity Leadership Theory offers a new way of perceiving leadership - a theoretical framework for approaching the study of leadership that moves beyond the managerial logics of the Industrial Age to meet the new leadership requirements of the Knowledge Era.

\section{References}

Achtenhagen et al., 2003 - L. Achtenhagen, L. Melin, T. Mullern, and T. Ericson, Leadership: The role of interactive strategizing. In: A. Pettigrew, R. Whittington, L. Melin, C. Sanchez-Runde, F.A.J. Van Den Bosch, W. Ruigrok, and T. Numagami, Editors, Innovative forms of organizing: International perspectives, Sage Publications, London (2003), pp. 49-71.

Allen, 2001 - P. Allen, A complex systems approach to learning in adaptive networks, International Journal of Innovation Management $\mathbf{5}$ (2001), pp. 149-180.

Alvesson \& Sveningsson, 2003 - M. Alvesson and S. Sveningsson, The great disappearing act: Difficulties in doing "leadership", The Leadership Quarterly 14 (2003), pp. 359-381.

Arthur, 1989 - W. B. Arthur, The economy and complexity. In: D.L. Stein, Editor, Lectures in the sciences of complexity vol. 1, AddisonWesley, Redwood City, CA (1989), pp. 713-740.

Ashby, 1960 - W. R. Ashby, Design for a brain (2nd Ed.), Wiley, New York (1960).

Bak, 1996 - P. Bak, How nature works, Copernicus, New York (1996).

Bamford et al., 2002 - J. D. Bamford, B. Gomes-Casseres, and M.S. Robinson, Mastering alliance strategy, Jossey Bass, San Francisco, CA (2002).

Barkema et al., 2002 - H. G. Barkema, J. A. C. Baum, and E. A. Mannix, Management challenges in a new time, Academy of Management Journal 45 (5) (2002), pp. 916-930.

Barnard, 1938 - C.I. Barnard, The functions of the executive, Harvard University Press, Cambridge, MA (1938).

Bass, 1985 - B. M. Bass, Leadership and performance beyond expectations, Free Press, New York (1985).

Bedeian \& Hunt, 2006 - A. G. Bedeian and J. G. Hunt, Academic amnesia and vestigial assumptions of our forefathers, The Leadership Quarterly 17 (2) (2006), pp. 190-205.

Bennis, 1996 - W. G. Bennis, Becoming a leader of leaders. In: R. Gibson, Editor, Rethinking the future, Brealey, London (1996).

Bettis \& Hitt, 1995 - R. A. Bettis and M. A. Hitt, The new competitive landscape, Strategic Management Journal 7 (13) (1995), pp. 7-19.

Bluedorn et al., 1994 - A. C. Bluedorn, R. A. Johnson, D. K. Cartwright, and B. R. Barringer, The interface and convergence of the strategic management and organizational environment domains, Journal of Management 20 (2) (1994), pp. 201-262.

Boal \& Schlultz, 2007 - K. Boal and P. Schlultz, Storytelling, time, and evolution: The role of strategic leadership in complex adaptive systems, The Leadership Quarterly 18 (2007), pp. 411-428.

Boal et al., 1992 - K. Boal, C. J. Whitehead, R. Phillips, and J. Hunt, Strategic leadership: A multiorganizational-level perspective, Quorum, Westport, CT (1992).

Boisot, 1998 - M. H. Boisot, Knowledge assets: Securing competitive advantage in the information economy, Oxford University Press, Oxford (1998).

Bonabeau \& Meyer, 2001 - E. Bonabeau and C. Meyer, Swarm intelligence: A whole new way to think about business, Harvard Business Review 79 (5) (2001), pp. 107-114.

Bradbury \& Lichtenstein, 2000 - H. Bradbury and B. Lichtenstein, Relationality in organizational research: Exploring the space between, Organization Science 11 (2000), pp. 551-564.

Carley, 1997 - K. Carley, Organizational adaptation, Annals of Operation Research 75 (1997), pp. 25-47.

Carley \& Hill, 2001 - K. Carley and V. Hill, Structural change and learning within organizations. In: A. Lomi and E. R. Larsen, Editors, Dynamics of organizational societies, AAAI/MIT Press, Cambridge, MA (2001), pp. 63-92.

Carley \& Lee, 1998 - K. Carley and J.S. Lee, Dynamic organizations: Organizational adaptation in a changing environment, Advances in Strategic Management: A Research Annual 15 (1998), pp. 269-297.

Carley \& Ren, 2001 - K. Carley and Y. Ren, Tradeoffs between performance and adaptability for c ${ }^{3} \mathrm{i}$ architectures (part of the A2C2 project supported in part by the Office of Naval Research), Carnegie Mellon University (2001).

Carley \& Svoboda, 1996 - K. Carley and D. M. Svoboda, Modeling organizational adaptation as a simulated annealing process, Sociological Methods and Research 25 (1) (1996), pp. 138-168.

Child \& McGrath, 2001 - J. Child and R. G. McGrath, Organizations unfettered: Organizational form in an information-intensive economy, The Academy of Management Journal 44 (6) (2001), pp. 1135-1149.

Cilliers, 1998 - P. Cilliers, Complexity and postmodernism: Understanding complex systems, Routledge, London (1998).

Cilliers, 2001 - P. Cilliers, Boundaries, hierarchies and networks in complex systems, International Journal of Innovation Management 5 (2001), pp. 135-147. 
Cohen et al., 1972 - M. D. Cohen, J. G. March, and J. P. Olsen, A garbage can model of organizational choice, Administrative Science Quarterly 17 (1972), pp. 1-25.

Conger, 1999 - J. A. Conger, Charismatic and transformational leadership in organizations: An insider's perspective on these developing streams of research, The Leadership Quarterly 10 (2) (1999), pp. 145-179.

Coveney, 2003 - P. Coveney, Self-organization and complexity: A new age for theory, computation and experiment, Paper presented at the Nobel symposium on self-organization, Karolinska Institutet, Stockholm (2003).

Cusumano, 2001 - M. Cusumano, Focusing creativity: Microsoft's "synch and stabilize" approach to software product development. In: I. Nonaka and T. Nishiguchi, Editors, Knowledge emergence: Social, technical, and evolutionary dimensions of knowledge creation, Oxford University Press, Oxford (2001).

Davenport, 2001 - T. H. Davenport, Knowledge work and the future of management. In: W. G. Bennis, G. M. Spreitzer, and T. G. Cummings, Editors, The future of leadership: Today's top leadership thinkers speak to tomorrow's leaders, Jossey-Bass, San Francisco (2001), pp. 41-58.

Day, 2000 - D. V. Day, Leadership development: A review in context, The Leadership Quarterly 11 (4) (2000), pp. 581-613.

Dooley, 1996 - K.J. Dooley, Complex adaptive systems: A nominal definition (1996, 10.26.96) Retrieved September, 2006, from http://0www.eas.asu.edu.library.unl.edu:80/ kdooley/casopdef.html

Dougherty, 1996 - D. Dougherty, Organizing for innovation. In: S.R. Clegg, C. Hardy and W. Nord, Editors, Handbook of organization studies, Sage, London (1996), pp. 424-439.

Dougherty \& Hardy, 1996 - D. Dougherty and C. Hardy, Sustained product innovation in large, mature organizations: Overcoming innovation-to-organization problems, Academy of Management Journal 39 (1996), pp. 1120-1153.

Drath, 2001 - W. Drath, The deep blue sea: Rethinking the source of leadership, Jossey-Bass and Center for Creative Leadership, San Francisco (2001).

Drucker, 1998 - P. F. Drucker, Management's new paradigms (cover story), Forbes 162 (7) (1998), pp. 152-170.

Drucker, 1999 - P. F. Drucker, Management challenges for the 21st century, HarperCollins, New York (1999).

Eisenhardt, 1989 - K. Eisenhardt, Making fast strategic decisions in high-velocity environments, Academy of Management Journal 32 (1989), pp. 543-576.

Finkelstein \& Hambrick, 1996 - S. Finkelstein and D. C. Hambrick, Strategic leadership: Top executives and their effects on organizations, West Publishing Co, St. Paul, MN (1996).

Fletcher, 2004 - J. K. Fletcher, The paradox of postheroic leadership: An essay on gender, power, and transformational change, Leadership Quarterly 15 (2004), pp. 647-661.

Goodwin, 1994 - B. Goodwin, How the leopard changed its spots: The evolution of complexity, Charles Scribner's Sons, New York (1994).

Gronn, 1999 - P. Gronn, A realist view of leadership, Paper presented at the educational leaders for the new millenium-leaders with soul. ELOAusAsia On-line Conference (1999).

Gronn, 2002 - P. Gronn, Distributed leadership as a unit of analysis, The Leadership Quarterly 13 (2002), pp. 423-451.

Guastello, 2007 - S. Guastello, Nonlinear dynamics and leadership emergence, The Leadership Quarterly 18 (2007), pp. $357-369$.

Halal, 1998 - W. E. Halal, Editor, The infinite resource: Mastering the boundless power of knowledge, Jossey-Bass, New York (1998).

Halal \& Taylor, 1999 - W. E. Halal and K. B. Taylor, Editors, Twenty-first century economics: Perspectives of socioeconomics for a changing world, Macmillan, New York (1999).

Hales, 2002 - C. Hales, 'bureaucracy-lite' and continuities in managerial work, British Journal of Management vol. 13, Blackwell Publishing Limited (2002) 51. pp.

Hazy, 2007 - J. Hazy, Computer models of leadership: Foundations for a new discipline or meaningless diversion?, The Leadership Quarterly 18 (2007), pp. 391-410.

Heckscher, 1994 - C. Heckscher, Defining the post-bureaucratic type. In: C. Heckscher and A. Donnellon, Editors, The post-bureaucratic organization: New perspectives on organizational change, Sage, Thousand Oaks (1994).

Hedlund, 1994 - G. Hedlund, A model of knowledge management and the N-form corporation, Strategic Management Journal 15 (1994), pp. 73-90.

Heifetz, 1994 - R. A. Heifetz, Leadership without easy answers, Cambridge Harvard University Press (1994).

Heifetz \& Laurie, 2001 - R. A. Heifetz and D.L. Laurie, The work of leadership, Harvard Business Review 79 (11) (2001), pp. 131-141.

Heifetz \& Linsky, 2002 - R. A. Heifetz and M. Linsky, Leadership on the line: Staying alive through the dangers of leading, Harvard University Press, Boston (2002).

Henrickson \& McKelvey, 2002 - L. Henrickson and B. McKelvey, Foundations of new social science: Institutional legitimacy from philosophy, complexity science, postmodernism, and agent-based modeling, Proceedings of the National Academy of Sciences 99 (Supp. 3) (2002), pp. 7288-7297.

Hernes, 1998 - G. Hernes, Real virtuality. In: P. Hedström and R. Swedberg, Editors, Social mechanisms: An analytical approach to social theory, Cambridge University Press, Cambridge (1998), pp. 74-101.

Hitt, 1998 - M. A. Hitt, Presidential address: Twenty-first century organizations: Business firms, business schools, and the academy, The Academy of Management Review 23 (1998), pp. 218-224.

Hogue \& Lord, 2007 - M. Hogue and R. G. Lord, A multilevel, complexity theory approach to understanding gender bias in leadership, The Leadership Quarterly 18 (2007), pp. 370-390.

Holland, 1995 - J. H. Holland, Hidden order, Addison-Wesley Publishing Company, Reading, MA (1995).

Homans, 1950 - G. C. Homans, The human group, Harcourt, Brace and World, New York (1950).

Hosking, 1988 - D. M. Hosking, Organizing, leadership and skilful process, Journal of Management Studies 25 (1988), pp. 147-166.

House \& Mitchell, 1974 - R. J. House and T. Mitchell, A path-goal theory of leader effectiveness, Journal of Contemporary Business (1974), pp. 81-97.

Howell \& Boies, 2004 - J. M. Howell and K. Boies, Champions of technological innovation: The influence of contextual knowledge, role orientation, idea generation, and idea promotion on champion emergence, The Leadership Quarterly 15 (1) (2004), pp. 123-143.

Hunt, 1999 - J. Hunt, Transformational/charismatic leadership's transformation of the field: A historical essay, The Leadership Quarterly 10 (2) (1999), pp. 129-144. 
Hunt \& Ropo, 1995 - J. Hunt and A. Ropo, Multi-level leadership-grounded theory and mainstream theory applied to the case of general motors, The Leadership Quarterly 6 (3) (1995), pp. 379-412.

Huxham \& Vangen, 2000 - C. Huxham and S. Vangen, Leadership in the shaping and implementation of collaboration agendas: How things happen in a (not quite) joined-up world, Academy of Management Journal 43 (6) (2000), pp. 1159-1175.

Ilinitch et al.,1996 - A. Y. Ilinitch, R. A. D' Aveni, and A. Lewin, New organizational forms and strategies for managing in hypercompetitive environments, Organization Science 7 (1996), pp. 211-220.

Jaques, 1989 - E. Jaques, Requisite organization, Cason Hall, Arlington, VA (1989).

Jaussi \& Dionne, 2003 - K. S. Jaussi and S. D. Dionne, Leading for creativity: The role of unconventional leadership behavior, The Leadership Quarterly 14 (2003), pp. 475-498.

Jehn, 1997 - K. A. Jehn, A qualitative analysis of conflict types and dimensions in organizational groups, Administrative Science Quarterly 42 (1997), pp. 530-557.

Jennings \& Haughton, 2000 - J. Jennings and L. Haughton, It's not the big that eat the small...it's the fast that eat the slow, HarperBusiness, New York (2000).

Jones, 2000 - G. R. Jones, Organizational theory (3rd ed.), Addison-Wesley, Reading, MA (2000).

Kauffman, 1993 - S. A. Kauffman, The origins of order, Oxford University Press, New York (1993).

Kontopoulos, 1993 - K. M. Kontopoulos, The logics of social structure, Cambridge University Press, Cambridge (1993).

Krause, 2004 - D. E. Krause, Influence-based leadership as a determinant of the inclination to innovate and of innovation-related behaviors: An empirical investigation, The Leadership Quarterly 15 (1) (2004), pp. 79-102.

Lencioni, 2002 - P. Lencioni, The five dysfunctions of a team: A leadership fable, Jossey-Bass, San Francisco (2002).

Levy, 1992 - S. Levy, Artificial life: The quest for new creation, Random House, New York (1992).

Lewin, 1952 - A. Lewin, Group decision and social change. In: G. E. Swanson, T. M. Newcomb and E.L. Hartley, Editors, Readings in social psychology, rev. ed., Holt, New York (1952), pp. 459-473.

Lewin, 1992 - R. Lewin, Complexity: Life at the edge of chaos, Macmillan Publishing Company, New York (1992).

Lewin, 1999 - R. Lewin, Complexity: Life at the edge of chaos (2nd ed.), University of Chicago Press, Chicago (1999).

Lichtenstein et al., 2006 - B. Lichtenstein, M. Uhl-Bien, R. Marion, A. Seers, D. Orton, and C. Schreiber, Complexity Leadership Theory: An interactive perspective on leading in complex adaptive systems, Emergence: Complexity and Organization 8 (4) (2006), pp. 2-12.

Lorenz, 1993 - E. Lorenz, The essence of chaos, University of Washington Press, Seattle (1993).

Mackenzie, 2006 - K. Mackenzie, The LAMPE theory of organizational leadership. In: F. Yammarino and F. Dansereau, Editors, Research in multi-level issues vol. 5, Elsevier Science, Oxford, UK (2006).

Mandelbrot, 1983 - B. B. Mandelbrot, The fractal geometry of nature, W. H. Freeman, New York (1983).

Manville \& Ober, 2003 - B. Manville and J. Ober, Beyond empowerment: Building a company of citizens, Harvard Business Review (2003, Jan.), pp. 48-53.

Marion, 1999 - R. Marion, The edge of organization: Chaos and complexity theories of formal social organizations, Sage, Newbury Park, CA (1999).

Marion \& Uhl-Bien, 2001 - R. Marion and M. Uhl-Bien, Leadership in complex organizations, The Leadership Quarterly 12 (2001), pp. 389-418.

Marion \& Uhl-Bien, 2003 - R. Marion and M. Uhl-Bien, Complexity theory and Al-Qaeda: Examining complex leadership, Emergence: A Journal of Complexity Issues in Organizations and Management 5 (2003), pp. 56-78.

Marion \& Uhl-Bien, 2007 - R. Marion and M. Uhl-Bien, Complexity and strategic leadership. In: R. Hooijberg, J. Hunt, J. Antonakis, K. Boal, and N. Lane, Editors, Being there even when you are not: Leading through structures, systems, and processes, Elsevier, Amsterdam (2007).

McKelvey, 2001 - B. McKelvey, Energizing order-creating networks of distributed intelligence, International Journal of Innovation Management 5 (2001), pp. 181-212.

McKelvey, in press - B. McKelvey, Emergent strategy via Complexity Leadership: Using complexity science and adaptive tension to build distributed intelligence. In: M. Uhl-Bien \& R. Marion (Eds.), Complexity and leadership volume I: Conceptual foundations. Charlotte, NC: Information Age Publishing (in press).

McKelvey \& Boisot, 2003 - B. McKelvey and M. H. Boisot, Transcendental organizational foresight in nonlinear contexts, Paper presented at the INSEAD Conference on Expanding Perspectives on Strategy Processes, Fontainebleau, France (2003).

McKelvey et al., 2003 - B. McKelvey, R. Marion, and M. Uhl-Bien, A simple-rule approach to CEO leadership in the 21st century, Paper presented at the University of Lecce Conference on New Approaches to Strategic Management, Ostuni, Italy (2003).

McKelvey et al., 1999 - B. McKelvey, H. Mintzberg, T. Petzinger, L. Prusak, P. Senge, and R. Shultz, The gurus speak: Complexity and organizations, Emergence: A Journal of Complexity Issues in Organizations and Management 1 (1) (1999), pp. 73-91.

Miles, 1998 - R.E. Miles, The spherical network organization. In: W. E. Halal, Editor, The infinite resource: Creating and leading the knowledge enterprise, Jossey-Bass, San Francisco (1998), pp. 111-121.

Miles et al., 1999 - R. E. Miles, C. C. Snow, J. A. Matthews, and G. Miles, Cellular-network organizations. In: W. E. Halal and K. B. Taylor, Editors, Twenty-first century economics, Macmillan, New York (1999), pp. 155-173.

Mumford et al., in press - M. Mumford, K. E. Bedell-Avers, and S. T. Hunter, Planning for innovation: A multi-level perspective. In: M.D. Mumford, S.T. Hunter and K.E. Bedell (Eds.), Research in multi-level issues. Oxford, GB: Elsevier (in press).

Mumford et al., 2003 - M. Mumford, S. Connelly, and B. Gaddis, How creative leaders think: Experimental findings and cases, The Leadership Quarterly 14 (4/5, Pt.1) (2003), pp. 411-432.

Mumford \& Licuanan, 2004 - M. D. Mumford and B. Licuanan, Leading for innovation: Conclusions, issues, and directions, The Leadership Quarterly 15 (1) (2004), pp. 163-171.

Mumford et al., 2002 - M. D. Mumford, R. A. Schultz, and H. K. Osborn, Planning in organizations: Performance as a multi-level phenomenon. In: F. J. Yammarino and F. Dansereau, Editors, Research in multi-level issues: The many faces of multi-level issues, Elsevier, Oxford, GB (2002), pp. 3-35.

Mumford et al., 2002 - M. D. Mumford, G. M. Scott, B. Gaddis, and J.M. Strange, Leading creative people: Orchestrating expertise and relationships, The Leadership Quarterly 13 (6) (2002), pp. 705-750. 
Nonaka \& Nishiguchi, 2001 - I. Nonaka and T. Nishiguchi, Introduction: Knowledge emergence. In: I. Nonaka and T. Nishiguchi, Editors, Knowledge emergence: Social, technical, and evolutionary dimensions of knowledge creation, Oxford University Press, Oxford (2001), pp. 3-9.

Osborn \& Hunt, 2007 - R. Osborn and J. Hunt, Leadership and the choice of order: Complexity and hierarchical perspectives near the edge of chaos, The Leadership Quarterly 18 (2007), pp. 319-340.

Osborn et al., 2002 - R. Osborn, J. G. Hunt, and L. R. Jauch, Toward a contextual theory of leadership, The Leadership Quarterly 13 (2002), pp. 797-837.

Parks, 2005 - S. D. Parks, Leadership can be taught: A bold approach for a complex world, Harvard Business School Press, Boston (2005).

Pearce \& Conger, 2003 - C. L. Pearce and J. A. Conger, Shared leadership: Reframing the hows and whys of leadership, Sage, Thousand Oaks (2003).

Pfeffer, 2005 - J. Pfeffer, Producing sustainable competitive advantage through the effective management of people, The Academy of Management Executive 19 (4) (2005), pp. 95-108.

Phillips \& Hunt, 1992 - R. Phillips and J. Hunt, Editors, Strategic leadership: A multiorganizational-level perspective, Quorum Books, Westport, CT (1992).

Plowman et al., 2007a - D. Plowman, L. T. Baker, T. Beck, M. Kulkarni, S. Solansky, and D. Travis, Radical change accidentally: The emergence and amplification of small change, Academy of Management Journal 50 (3) (2007).

Plowman et al., 2007b - D. Plowman, L. T. Baker, T. Beck, M. Kulkarni, S. Solansky, and D. Travis, The role of leadership in emergent, self-organization, The Leadership Quarterly 18 (2007), pp. 341-356.

Plowman \& Duchon, in press - D. Plowman and D. Duchon, Dispelling the myths about leadership: From cybernetics to emergence. In: M. Uhl-Bien \& R. Marion (Eds.), Complexity and leadership volume I: Conceptual foundations. Charlotte, NC: Information Age Publishing (in press).

Popper, 1986 - K. R. Popper, The poverty of historicism, Routledge, London (1986).

Prigogine, 1997 - I. Prigogine, The end of certainty, The Free Press, New York (1997).

Prusak, 1996 - L. Prusak, The knowledge advantage, Strategy \& Leadership 24 (1996), pp. 6-8.

Quinn et al., 2002 - J.B. Quinn, P. Anderson, and S. Finkelstein, Managing professional intellect: Making the most of the best. In: S. Little, P. Quintas, and T. Ray, Editors, Managing knowledge: An essential reader, Sage, London (2002), pp. 335-348.

Reiter-Palmon \& Illies, 2004 - R. Reiter-Palmon and J. J. Illies, Leadership and creativity: Understanding leadership from the creative problem-solving perspective, The Leadership Quarterly 15 (2004), pp. 55-77.

Rost, 1991 - J. C. Rost, Leadership for the twenty-first century, Praeger, London (1991).

Roy, 1954 - D. Roy, Efficiency and 'the fix': Informal intergroup relations in a piecework machine shop, American Journal of Sociology 60 (1954), pp. 255-266.

Schilling \& Steensma, 2001 - M. A. Schilling and H. K. Steensma, The use of modular organizational forms: An industry level analysis, Academy of Management Journal 44 (6) (2001), pp. 1149-1168.

Schneider, 2002 - M. Schneider, A stakeholder model of organizational leadership, Organization Science 13 (2) (2002), pp. 209-220.

Schneider \& Somers, 2006 - M. Schneider and M. Somers, Organizations as complex adaptive systems: Implications of complexity theory for leadership research, The Leadership Quarterly 17 (4) (2006), pp. 351-365.

Schreiber, 2006 - Schreiber, C. (2006). Human and organizational risk modeling: Critical personnel and leadership in network organizations. Unpublished Dissertation, Carnegie Mellon, Pittsburgh, PA.

Selznick, 1948 - P. Selznick, Foundations of the theory of organizations, American Sociological Review 13 (1948), pp. 25-35.

Selznick, 1957 - P. Selznick, Leadership in administration, Harper and Row, New York (1957).

Shalley \& Gilson, 2004 - C. E. Shalley and L. L. Gilson, What leaders need to know: A review of social and contextual factors that can foster or hinder creativity, The Leadership Quarterly 15 (1) (2004), pp. 33-53.

Simon, 1962 - H. A. Simon, The architecture of complexity, Proceedings of the American Philosophical Society 106 (1962), pp. 467-482.

Snyder, 1988 - R. C. Snyder, New frames for old: Changing the managerial culture of an aircraft factory. In: M. O. Jones, M. D. Moore and R. C. Snyder, Editors, Inside organizations: Understanding the human dimension, Sage Publications, Newbury Park, CA (1988), pp. 191-208.

Stacey et al., 2000 - R. D. Stacey, D. Griffin, and P. Shaw, Complexity and management: Fad or radical challenge to systems thinking, Routledge, London and New York (2000).

Sterman, 1994 - J. D. Sterman, Learning in and about complex systems, System Dynamics Review 10 (1994), pp. 291-330.

Streatfield, 2001 - P. J. Streatfield, The paradox of control in organizations, Routledge, London (2001).

Thomas et al., 2005 - C. Thomas, R. Kaminska Labbé, and B. McKelvey, Managing the MNC and exploitation/exploration dilemma: From static balance to dynamic oscillation. In: G. Szulanski, Y. Doz and J. Porac, Editors, Advances in strategic management: Expanding perspectives on the strategy process Vol. 22, Elsevier, Amsterdam, NL (2005), pp. 213-250.

Volberda, 1996 - H. W. Volberda, Toward the flexible form: How to remain vital in hypercompetitive environments, Organization Science 7 (4) (1996), p. 359.

Weick, 1976 - K. E. Weick, Educational organizations as loosely coupled systems, Administrative Science Quarterly 21 (1976), pp. 1-19.

Weisburg, 1999 - R. Weisburg, Creativity and knowledge: A challenge to theories. In: R. J. Sternberg, Editor, Handbook of creativity, Cambridge University Press, Cambridge, GB (1999), pp. 226-259.

Wikipedia, n.d. - Wikipedia. (n.d.). Self organization [Electronic Version]. Retrieved 2006 from http://en.wikipedia.org/wiki/Selforganization

Yukl, 2005 - G. Yukl, Leadership in organizations (6th ed.), Prentice Hall, Englewood Cliffs, NJ (2005).

Zaccaro \& Klimoski, 2001 - S. J. Zaccaro and R. J. Klimoski, The nature of organizational leadership: An introduction. In: S. J. Zaccaro and R. J. Klimoski, Editors, The nature of organizational leadership, Jossey Bass, San Francisco (2001), pp. 3-41.

Zohar, 1997 - D. Zohar, Rewiring the corporate brain, Berrett-Koehler, San Francisco (1997). 